\title{
Effect of Dietary Microalgae on Growth Performance, Profiles of Amino and Fatty Acids, Antioxidant Status, and Meat Quality of Broiler Chickens
}

\author{
Sabry El-Bahr 1,2,*(D), Saad Shousha ${ }^{1,3}$, Ahmed Shehab ${ }^{4}$, Wassem Khattab ${ }^{4}$, \\ Omar Ahmed-Farid ${ }^{5}$, Islam Sabike ${ }^{6}$, Osama El-Garhy ${ }^{7}$, Ibrahim Albokhadaim ${ }^{1}$ \\ and Khaled Albosadah ${ }^{1}$ \\ 1 Department of Biomedical Sciences, College of Veterinary Medicine, King Faisal University, Al-Ahsa 31982, \\ Box 400, Saudi Arabia; smmohamed@kfu.edu.sa (S.S.); ialbokhadaim@kfu.edu.sa (I.A.); \\ kbusadah@kfu.edu.sa (K.A.) \\ Department of Biochemistry, Faculty of Veterinary Medicine, Alexandria University, Alexandria 21526, Egypt \\ Department of Physiology, Faculty of Veterinary Medicine, Benha University, Benha 13518, Egypt \\ 4 Department of Nutrition and Clinical Nutrition, Faculty of Veterinary Medicine, Benha University, \\ Moshtohor, Qalioubia, Benha 13518, Egypt; ahmedshehab@fvtm.bu.edu.eg (A.S.); \\ wasimhassan@fvtm.bu.edu.eg (W.K.) \\ 5 Department of Physiology, National Organization for Drug Control and Research, Giza 12622, Egypt; \\ ebntaimya@yahoo.com \\ 6 Department of Food Hygiene, Faculty of Veterinary Medicine, Benha University, Benha 13518, Egypt; \\ islamsabek@fvtm.bu.edu.eg \\ 7 Department of Animal Production, Faculty of Agriculture, Benha University, Moshtohor, Qalioubia, \\ Benha 13518, Egypt; osama.elsayed1977@yahoo.com \\ * Correspondence: selbahar@kfu.edu.sa
}

Received: 20 March 2020; Accepted: 20 April 2020; Published: 27 April 2020

Simple Summary: The use of feed additives with no side effectsfor enhancing growth performance and improving meat quality in broilers chickens is an essential research topic. In these regards, this study aimed to evaluate the impact of three species of microalgae namely Chlorella vulgaris (CV), Spirulina platensis (SP) and Amphora coffeaformis (AC) on growth performance, profiles of fatty and amino acids, antioxidant status and meat quality of breast muscles. The results demonstrated that the inclusion of studied microalgae notably $\mathrm{AC}$ has a positive effect on performance, antioxidant status and meat quality of breast muscle in broiler chickens.

\begin{abstract}
The study used 96 broiler chickens to evaluate the impact of three species of microalgae on performance, profiles of fatty and amino acids, antioxidants, and meat quality of breast muscles. Birds were divided into four groups ( 24 birds/each) with 4 replicates ( 6 birds each). Birds in the first group were fed basal diet and served as a control (C). Birds of 2-4 groups were fed basal diet mixed with same dose (1 g/kg diet) of Chlorella vulgaris (CV), Spirulina platensis (SP), and Amphora coffeaformis (AC). At the age of 36 days, performance parameters were reported, and breast muscle samples were collected and stored frozen at $-80^{\circ} \mathrm{C}$. AC shared $\mathrm{CV}$ in the superiority of increasing final body weight and body weight gain compared to SP and control. AC shared SP in the superiority of increasing the level of essential fatty and amino acids and decreasing the microbial growth in breast muscle compared to CV and control. All studied microalgae reduced malondialdehyde (MDA) and protein carbonyl (PC) levels, cooking loss, and aerobic plate count (APC) and increased the superoxide dismutase (SOD) activities in breast muscle compared to control. The current study indicated that studied microalgae, notably AC, can be used to enhance performance and meat quality in broilers chickens.
\end{abstract}


Keywords: Chlorella vulgaris; Spirulina platensis; Amphora coffeaformis; meat quality; biomarkers

\section{Introduction}

The rapid growth of chicken broilers, the availability of its high-quality meat at low sales prices, and its rapid response to changes in ration composition have increased the researchers attention to producing chicken meat enriched with functional ingredients [1]. Antibiotics have been widely used in diets of livestock for many years to control disease and improve production performance [2]. However, there is a global trend to reducing their use in poultry feeds to avoid the risk of antibiotic residues in meat and minimize the development of antibiotic resistance [3-6]. Therefore, the addition of antibiotics as growth promotersin animal diet has been prohibited [7] Hence, searching for potential growth promoting alternatives with no side effects is very essential [8]. Different kinds of phytogenic feed additives, especially marine plants and other natural materials, were used to improve animal health and production due to their anti-inflammatory, immunomdulatory, antioxidant, and antibacterial activities [9]. Microalgae are unicellular, photosynthetic, and microscopic algae live in marine and fresh water that contains several biological active components such as omega-3 (n-3) long chain polyunsaturated fatty acids (LC-PUFA), essential amino acids, antioxidants, and carotenoids [10]. During the last decade, the beneficial feeding effects of microalgae have been advertised extensively all over the world, making the algae production enterprises begin to spread among small and large producer's levels [11]. Spirulina platensis (SP) is a prokaryotic cell type blue green algae and is some time called cyanobacteria [12]. Dried SP is a rich source of protein, essential fatty acids, vitamins and carotenoids, so it can be used for human and animal feeding [13]. Chlorella vulgaris (CV) is a green microalgae, unicellular live in freshwater and is a rich source of essential aminoacids, vitamins, minerals, antioxidants, and carotenoids [14]. The antibacterial, antioxidant, hypolipidemic, immunomodulatory, and anti-inflamatory effects of SP and CV have been studied in both laboratory animals [15] and livestock as well as poultry $[16,17]$. Recently, three weeks administration of SP for broilers resulted in similar or even better responses than administration of in-feed antibiotics during the whole rearing period [18]. Amphora coffeaformis (AC) exert potent antioxidant effect against lipid peroxidation [19], and rich in polyunsaturated fatty acids (PUFAs), especially $\alpha$-linolenic acid, eicosapentaenoic (EPA), and docosahexaenoic (DHA) [20]. However, little literature is available about dietary supplementation of AC.

Microalgae improved the fatty acids profile but failed to improve the growth performance, carcass, traits, color, $\mathrm{pH}$, oxidative stability, chemical composition, and sensory characteristics in Muscovy ducks [21]. On the contrary, microalgae, especially SP and CV, improved the growth performance and meat quality through enrichment of broiler meat with n-3 polyunsaturated fatty acids (PUFA) and carotenoids [12]. Furthermore, microalgae demonstrated antimicrobial activities against spoilage and foodborne microorganisms, therefore trials are still seeking to validate it as potential alternatives to traditional preservatives [22]. Many algal compounds including proteins, amino acids, PUFA, especially eicosapentaenoic (EPA), docosahexaenoic (DHA), polysaccharides, and antioxidants have demonstrated antimicrobial potential [23], but the primary algal components responsible for antimicrobial functionality are still a relatively incipient field of research [24]. Even so, comparative studies investigating the effect of different species of microalgae on different axis such as fatty and amino acids composition, antioxidant status, and meat quality parameters in broiler chicken meat are needed. Therefore, the current study was conducted to evaluate impact of dietary dried microalgae supplementation on the growth and meat quality parameters of broiler chickens. 


\section{Materials and Methods}

\subsection{Birds, Diets, and Experimental Design}

Experimental procedures and management conditions used in this study were carried out in accordance with the national institute of health guidelines for the care and the use (NIH Publications No.8023, revised 1978) and approved by Animal Care and Use Committee of Benha University, Faculty of Veterinary Medicine, Egypt (BUFVTM; permission \# 282019 at 02 August 2019). A total number of 96 one day old Cobb 500 broiler chicks (mixture of male and female) were purchased from certified Cobb breeder flock of hens (Benha, Egypt). The day-old chicks were transferred to Poultry research Farm, Faculty of Agriculture, Benha University, Egypt where the field experiment was conducted. At their 4 th day of age, birds were weighed $(73.54 \pm 0.49)$ and then distributed in 16 pens ( 6 birds in a pen) at room temperature of $33{ }^{\circ} \mathrm{C}$. Temperature was maintained at $33^{\circ} \mathrm{C}$ during the first week and gradually decreased to $24^{\circ} \mathrm{C}$ by the end of the third week until the end of the experiment. The relative humidity maintained at 50-60\% during the experimental period. The air exchange range was $0.3 \mathrm{~m}^{3} / \mathrm{minute}^{2} / \mathrm{m}^{2}$. Birds were exposed to $23 \mathrm{~h}$ of white light a day and $1 \mathrm{~h}$ a dark. The intensity of light was 30-40 Lux from 0-7 day of age, thereafter the intensity was 5-10 Lux until the end of the experiment.

The pens provided a floor area of $1.5 \mathrm{~m}^{2}$ for each pen. The regular vaccination program applied to all birds. The birds of all groups were vaccinated against Newcastle disease virus (Hitchner B1) at day 7 in drinking water, infectious bursal disease virus (Gumbo L strain) at day 14 in drinking water, and Newcastle disease virus (La Sota) at day 21 of age in drinking water. The basal diet was formulated to meet the nutrient requirements of broiler chickens [25]. The composition of basal ground feed diet is displayed in Table 1. Throughout the experimental period (from 4 to 36 days of life), clean water and feeds were supplied ad libitum for broiler chickens. Birds were divided into four groups ( 24 birds for each) with 4 replicates ( 6 birds each; $4 \times 4 \times 6$ ). Birds in the first group were fed basal diet alone and served as a control (C). Birds of 2-4 groups were fed the basal diet supplemented with same dose (1 g/kg diet) of Chlorella vulgaris (CV), Spirulina platensis (SP), and Amphora coffeaformis (AC), for 32 days, respectively. The dried powder of the three microalgal species was obtained from the Algae Production Unit (APU), National Research Institute, Cairo, Egypt. The fatty and amino acids profiles of studied microalgae are illustrated at Tables 2 and 3, respectively. Fatty acid methyl ester (FAME) were used for quantitative determination of free fatty acids using gas chromatography (GC; Agilent Technologies Inc., Wilmington, DE, USA) equipped with SP2330 column (30 mm $\times 0.32 \mathrm{~mm} \times 0.2 \mu \mathrm{m}$ film thickness; Supelco Analytical, Bellefonte, PA, USA) and flame ionization detector. FAME peaks identified by comparison with retention times of mixture of fatty acids standards (Cat. No. 24073, Sigma-Aldrich, St. Louis, MO, USA) using Hewlett-Packard ChemStation software (Agilent). Fatty acids values were expressed as $\mathrm{mg} / \mathrm{g}$ dried powder [26-28]. Derivatized microalgae samples as well as amino acid standards (Sigma-Aldrich, St. Louis, MO, USA) were injected into the HPLC (Agilent HP 1200 series apparatus) equipped with Nova-PakTM C18 column $(4 \mu \mathrm{m}, 3.9 \times 4.6 \mathrm{~mm})$ for separation and quantification of free amino acids (mg/g dried powder) in studied microalgae [29]. 
Table 1. Ingredient composition and calculated nutrient analysis of starter (1-10 days), grower (11-25 days), and finisher (26-36 days) diets.

\begin{tabular}{cccc}
\hline Ingredients & 0-10 Days & 11-25 Days & 26-36 Days \\
\hline Yellow corn grains & 48.77 & 52 & 64.05 \\
Soybean meal 44\% & 34.32 & 33 & 25.00 \\
Corn gluten meal & 6.75 & 6 & 3.34 \\
Soybean oil & 5.86 & 5.21 & 3.97 \\
Limestone & 1.50 & 1.24 & 1.26 \\
Monocalcium phosphate & 1.75 & 1.50 & 1.35 \\
Choline chloride & 0.10 & 0.10 & 0.10 \\
Sodium chloride & 0.35 & 0.35 & 0.35 \\
1 Vitamin and mineral & 0.35 & 0.35 & 0.35 \\
premix & 0.14 & 0.14 & 0.17 \\
L-lysine HCl & 0.11 & 0.11 & 0.06 \\
DL-methionine & & & \\
Nutrient specifications & 3200 & 3200 & 3200 \\
2 ME Kcal/kg diet & 23 & 20 & 18 \\
CP (\%) & 1.00 & 0.9 & 0.77 \\
Ca (\%) & 0.46 & 0.45 & 0.38 \\
Available P (\%) & 0.50 & 0.45 & 0.37 \\
Methionine (\%) & 1.10 & 1.00 & 0.90 \\
Lysine (\%) & & &
\end{tabular}

${ }^{1}$ Vitamin and mineral premix supplied each $\mathrm{kg}$ of feeds with: Vitamin A $12000 \mathrm{IU}$; vitamin $\mathrm{D}_{3} 2000 \mathrm{IU}$; vitamin $\mathrm{E} 10 \mathrm{mg}$; vitamin $\mathrm{K}_{3} 2 \mathrm{mg}$; vitamin $\mathrm{B}_{1} 1 \mathrm{mg}$; vitamin $\mathrm{B}_{2} 5 \mathrm{mg}$; vitamin $\mathrm{B}_{6} 1.5 \mathrm{mg}$; vitamin $\mathrm{B}_{12} 0.01 \mathrm{mg}$; Biotin $0.05 \mathrm{mg}$; pantothenic acid $10 \mathrm{mg}$; Nicotinic acid $30 \mathrm{mg}$; Folic acid $1 \mathrm{mg}$; Manganese $60 \mathrm{mg}$; Iron $30 \mathrm{mg}$; Copper $10 \mathrm{mg}$; Iodine $1 \mathrm{mg}$; Selenium $0.01 \mathrm{mg}$; Cobalt $0.01 \mathrm{mg}$. ${ }^{2}$ ME: metabolizable energy.

Table 2. Concentrations of fatty acids ( $\mathrm{mg} / \mathrm{g}$ dried powder) in studied microalgae (Spirulina platensis (SP), Chlorella vulgaris (CV), and Amphora coffeaformis (AC)).

\begin{tabular}{cccc}
\hline Fatty Acid & SP & CV & AC \\
\hline Myristic (C14:0) & 3.15 & 6.91 & 5.18 \\
Plamitic (C16:0) & 26.91 & 59.85 & 40.17 \\
Stearic (C18:0) & 6.49 & 15.27 & 10.74 \\
Palmitoleic (C16:1) & 1.61 & 3.52 & 2.68 \\
Oleic (C18:1) & 2.44 & 6.36 & 3.88 \\
Linoleic (C18:2n-6) & 14.30 & 26.37 & 22.47 \\
-Linolenic (C18:3 n-3) & 4.46 & 11.82 & 6.94 \\
Archidic (C20:0) & 13.66 & 26.22 & 21.57 \\
EPA(C20:5 n-3) & 0.27 & 1.26 & 0.40 \\
DHA (C22:6 n-3) & 1.09 & 1.987 & 2.98 \\
\hline
\end{tabular}

CV: Chlorella vulgaris; SP: Spirulina platensis; AC: Amphora coffeaformis.

Table 3. Concentrations of amino acids ( $\mathrm{mg} / \mathrm{g}$ dried powder) in studied microalgae (SP, CV, and AC).

\begin{tabular}{cccc}
\hline Fatty Acid & SP & CV & AC \\
\hline Alanine & 55.17 & 46.70 & 59.37 \\
Arginine & 55.54 & 42.43 & 44.41 \\
Aspartic acid & 62.07 & 47.35 & 57.99 \\
Glutamic acid & 78.50 & 62.11 & 74.21 \\
Glycine & 36.67 & 33.07 & 36.27 \\
Histidine & 28.84 & 22.21 & 20.57 \\
Isoleucine & 17.89 & 15.11 & 14.30 \\
Leucine & 42.27 & 33.56 & 30.67 \\
Lysine & 25.30 & 21.97 & 28.14 \\
Methionine & 0.32 & $\mathrm{ND}$ & 0.30 \\
Phenyl alanine & 24.90 & 23.03 & 21.07 \\
Serine & 31.98 & 26.07 & 25.71 \\
Taurine & 1.86 & 1.68 & $\mathrm{ND}$ \\
Threonine & 29.50 & 26.81 & 30.53 \\
Tyrosine & 2.62 & $\mathrm{ND}$ & 0.78 \\
Valine & 28.16 & 22.88 & 27.68
\end{tabular}

CV: Chlorella vulgaris; SP: Spirulina platensis; AC: Amphora coffeaformis. 


\subsection{Growth Performance}

At the end of the experiment, performance parameters, namely body weight, body weight gain, and feed intake were estimated. Feed conversion ratio (FCR; $\mathrm{kg}$ feed/kg gain) was calculated by dividing feed intake with body weight [30].

\subsection{Collection of the Breast Meat Samples}

All chickens from each group were humanely euthanatized and samples from breast muscles (Pectoralis major) were dissected, cleaned, and stored frozen at $-80{ }^{\circ} \mathrm{C}$ for analysis of profiles of amino and fatty acids, antioxidant status and meat quality. Euthanasia was performed after sodium pentobarbital anesthesia $(20-30 \mathrm{mg} / \mathrm{kg})$ [31]. Sodium pentobarbital was injected to wing vein with sterilized needles.

\subsection{Determination of Profiles of Fatty and Amino Acids in Breast Muscles}

Chloroform and methanol $(2: 1 ; \mathrm{v} / \mathrm{v})$ solution was used to extract the total lipids from the breast muscle after vortexing for $2 \mathrm{~min}$ and centrifugation for $10 \mathrm{~min}$ at $1792 \mathrm{~g}$ [26]. The obtained supernatant was used to prepare the fatty acid methyl esters (FAME) by using methanol/sulphuric acid mixture (95:5) and hexane following esterification process as outlined earlier [28]. The obtained hexane extract of FAME were used for quantitative determination of free fatty acids using gas chromatography (GC; Agilent) equipped with SP2330 column $(30 \mathrm{~mm} \times 0.32 \mathrm{~mm} \times 0.2 \mu \mathrm{m}$ film thickness; Supelco Analytical, Bellefonte, PA, USA) and flame ionization detector [27]. FAME peaks identified by comparison with retention times of mixture of fatty acids standards (Cat. No. 24073, Sigma-Aldrich, St. Louis, MO, USA) using Hewlett-Packard ChemStation software (Agilent). Fatty acids values were expressed as $\mu \mathrm{g} / \mathrm{g}$ meat tissue. Homogenized breast meat samples were prepared, centrifuged, and filtrated [28] and then the filtrate was derivatized [32]. Derivatized samples as well as amino acid standards (Sigma-Aldrich, St. Louis, MO, USA) were injected into the HPLC (Agilent HP 1200 series apparatus, USA) equipped with Nova-PakTM C18 column $(4 \mu \mathrm{m}, 3.9 \times 4.6 \mathrm{~mm})$ for separation and quantification of free amino acids (nmol/g meat) according to the method described earlier [29] with some modifications [28].

\subsection{Determination of Antioxidant Status}

Malondialdhyde (MDA) was measured using HPLC (Agilent HP 1200 series apparatus) following protocols outlined earlier [33,34]. Briefly, an ice-cold 0.1 M Tris (hydroxymethyl) aminomethane- $\mathrm{HCl}$ (Tris- $\mathrm{HCl}$ ) was used to prepare a $10 \%$ muscle homogeneate $(\mathrm{w} / \mathrm{v})$ at $\mathrm{pH} 7.4$ by using an ice-cold homogeniser (Glas-Col, Terre Haute, IN, USA). The homogenate was then centrifuged at $2000 \times g$ at $4{ }^{\circ} \mathrm{C}$ for $15 \mathrm{~min}$ to eliminate nucleus and debris. The stock MDA standard solution of $1 \mathrm{mM}$ concentration was prepared by dissolving $25 \mu \mathrm{L}$ of 1,1,3,3 tetraethoxypropane (TEP) in $100 \mathrm{~mL}$ of water. Then, a $20 \mathrm{nmol} / \mathrm{mL}$ working standard was prepared by hydrolysis, for $2 \mathrm{~h}$ at room temperature, of $1 \mathrm{~mL}$ of TEP stock solution in $50 \mathrm{~mL}$ of sulfuric acid (1\%), which was again diluted with $1 \%$ sulfuric acid to achieve a final standard concentration of $1.25 \mathrm{nmol} / \mathrm{mL}$ for the assessment of the total MDA. Analytical column Supelcosil C18 ( $5 \mu \mathrm{m}$ particle size and 80 Ao pore size) $(250 \times 4.6$ ID), mobile phase 82.5:17.5 (v/v) of $30 \mathrm{mM}$ monobasic potassium phosphate ( $\mathrm{pH} 3.6)-$ methanol, a flow rate of $1.2 \mathrm{~mL} / \mathrm{min}$ and a wavelength of $250 \mathrm{~nm}$ were used for HPLC detection. The spectrophotometric assay described earlier Castegna, et al. [35] for estimating protein carbonyl (PC) from muscle samples was performed. Muscle samples were extracted in tricholoroacetic acid (TCA) by a final concentration of $10 \%(\mathrm{w} / \mathrm{v})$ for the derivatization step. The precipitates were then treated with $500 \mu \mathrm{L}$ of $0.2 \%$ dinitrophenylhyrdazine (DNPH) and incubated at room temperature for $1 \mathrm{~h}$ at $5 \mathrm{~min}$ intervals with vortexing. A total of $55 \mu \mathrm{L}$ of $100 \%$ TCA was added to precipitate the proteins. The subsequent pellets were centrifuged and washed three times with $500 \mu \mathrm{L}$ of ethanol:ethyl acetate mixture $(1: 1 ; \mathrm{v} / \mathrm{v})$. The pellet was then dissolved in $600 \mu \mathrm{L}$ of $6 \mathrm{M}$ of guanidine hydrochloride. The absorbance was determined at wavelength of $370 \mathrm{~nm}$ against an appropriate blank. Breast muscle tissue homogenate was prepared, centrifuged 
(4000 rpm for $15 \mathrm{~min}$ at $4{ }^{\circ} \mathrm{C}$ ) and the obtained supernatant was used to determine the superoxide dismutase (SOD) activity by using ELISA commercial kits (Cat \# SD 25 21; Biodiagnostic Company, Giza, Egypt) according to the manufacturer's instructions.

\subsection{Estimation of Meat Quality Parameters}

The collected breast muscles were used to analyze the quality parameters namely, $\mathrm{pH}$ after $24 \mathrm{~h}$ $\left(\mathrm{pH}_{24}\right)$, water holding capacity (WHC), thawing loss, and cooking loss. The $\mathrm{pH}_{24}$ of the collected breast muscles was recorded by using pH-meter (Jenway 3510 pH-meter, Cole-Parmer, Staffordshire, United Kingdom) $24 \mathrm{~h}$ post slaughtering. Three points calibration at 4, 7, and $10 \mathrm{pH}$ was used in the current study. The range was -2.000 to $19.999 \mathrm{pH}$; resolution was $0.001 / 0.01 / 0.1 \mathrm{pH}$ and the accuracy was $\pm 0.003 \mathrm{pH}$. The low-speed centrifugation method was conducted to estimate WHC of breast muscles, with a little modification. Briefly, about $10 \mathrm{~g}$ of intact breast muscle was placed and centrifuged in falcon tube containing glass beads at $10,000 \times g$ and $5{ }^{\circ} \mathrm{C}$ for $20 \mathrm{~min}$, then the precipitated meat was instantly removed, dried with filter paper, and reweighed again. The WHC was calculated as the percentage of loss in muscle samples weight after centrifugation [36]. Regarding thawing loss, the breast fillet was trimmed, wiped dry, then weighed (initial weight) and stored at $-18{ }^{\circ} \mathrm{C}$. After one week, the frozen breast fillets were thawed at $5{ }^{\circ} \mathrm{C}$ for $24 \mathrm{~h}$ and the final weight was calculated. The percentage of the difference between initial and final weight was the value of thawing loss [37]. Cooking loss was determined as described earlier [37]. Briefly, the muscle fillets were separately placed in thin-walled thermotolerant plastic bags in a water bath until core temperature reached $70{ }^{\circ} \mathrm{C}$, after which they were cooled to $5{ }^{\circ} \mathrm{C}$ in crushed ice, and reweighed again to calculate the cooking loss. Total aerobic plate count (APC) was conducted on the first day and after five days of chilling to evaluate the effect of supplemented microalgae on the overall microbiological quality of breast muscles. Representative chicken fillets for each group were immediately dissected from the carcasses under aseptic condition and part was allocated to the APC at the first day, while the other part was placed separately in sterile plastic bottles and held at $5{ }^{\circ} \mathrm{C}$ for further determination of APC after 5 days. Meat samples were prepared in the same way as for natural microflora of beef [38]. Briefly, a $10 \mathrm{~g}$ of chicken fillet were homogenized with a $90 \mathrm{~mL}$ sterile peptone solution $(0.1 \%)$ to make a $10 \%$ meat mixture. A serial 10-fold dilution of the samples homogenate was then prepared using sterile normal saline, and the dilutions of each sample were inoculated in duplicate into APC agar. The plates were then incubated at $37^{\circ} \mathrm{C}$ for $24-48 \mathrm{~h}$ before colonies were counted [39]. Then, the difference between APC (5th day) and APC (1st day) of chilling was calculated for each group to evaluate the preservative effect of supplemented microalgae on breast muscles.

\subsection{Statistical Analyses}

The collected data were exposed to one-way Analysis of Variance (ANOVA) using SPSS (version 16; IBM, Chicago, IL, USA) followed by Duncan's multiple comparison tests [40] to compare the differences between dietary treatments, where significant differences were observed $(p<0.05)$.

\section{Results}

\subsection{Effect of Dietary Microalgae on Growth Performance Parameters}

Data summarized in Table 4 indicated that the final body weight and body weight gain increased significantly $(p<0.05)$ in birds that received a diet supplemented with CV and AC compared to that of birds supplemented with SP which remained comparable to the control. However, the feed intake and feed conversion ratio (FCR) during the overall experimental period remained significantly unchanged $(p>0.05)$ in all experimental groups compared to the control (Table 4$)$. 
Table 4. Growth performance parameters of broilers chickens fed different species of microalgae for 32 days.

\begin{tabular}{|c|c|c|c|c|c|c|}
\hline \multirow{2}{*}{ Parameters } & \multicolumn{4}{|c|}{ Dietary Treatment } & \multirow{2}{*}{ SEM } & \multirow{2}{*}{$p$ Values } \\
\hline & Group 1 & Group 2 & Group 3 & Group 4 & & \\
\hline Body weight at 4 days (g) & 74.27 & 72.56 & 73.83 & 73.50 & 0.43 & 0.61 \\
\hline Body weight at 36 days $(\mathrm{g})$ & $1844^{\mathrm{b}}$ & $1990^{\mathrm{a}}$ & $1862.8^{b}$ & $1980.5^{\mathrm{a}}$ & 20.27 & 0.01 \\
\hline Body weight gain $(\mathrm{g})$ & $1770^{\mathrm{b}}$ & $1916^{\mathrm{a}}$ & $1788^{\mathrm{b}}$ & $1907^{\mathrm{a}}$ & 20.38 & 0.01 \\
\hline Feed intake $(\mathrm{g})$ & 3485 & 3517 & 3461 & 3500 & 14.38 & 0.32 \\
\hline Feed conversion ratio & 1.97 & 1.84 & 1.93 & 1.84 & 0.14 & 0.05 \\
\hline
\end{tabular}

${ }^{\mathrm{a}-\mathrm{b}}$ Means within a row not sharing a common superscript differ significantly when $(p<0.05)$. SEM: standard error of mean; Group 1: control; Group 2: Chlorella vulgaris (CV)-supplemented group; Group 3: Spirulina platensis (SP)-supplemented group; Group 4: Amphora coffeaformis (AC)-supplemented group.

\subsection{Effect of Dietary Microalgae on Profiles of Fatty and Amino Acids in Breast Muscles}

Fatty acid composition of breast muscle tissue of broiler chicken fed different species of microalgae is listed in Table 5. Eicosapentaenoic (EPA), docosahexaenoic (DHA), arachidonic acid (AA), polyunsaturated fatty acids (PUFA), and total n-3 fatty acids (n-3 FA) were increased significantly $(p<0.001)$ in breast muscle of birds supplemented with either SP or AC compared to that in birds received CV which remained comparable to control (Table 5). The presented data (Table 5) indicated that, the other fatty acid concentrations, total saturated fatty acids (SFA), total monounsaturated fatty acids (MUFA), and PUFA/SFA ratios remained unchanged significantly $(p>0.05)$ in all experimental groups compared to the control.

Table 5. Profiles of fatty acids in breast muscle of broilers chickens fed different species of microalgae for 32 days.

\begin{tabular}{|c|c|c|c|c|c|c|}
\hline \multirow{2}{*}{ Fatty Acids } & \multicolumn{4}{|c|}{ Dietary Treatment } & \multirow{2}{*}{ SEM } & \multirow{2}{*}{$p$ Values } \\
\hline & Group 1 & Group 2 & Group 3 & Group 4 & & \\
\hline Myristic (C14:0) & 0.71 & 0.70 & 0.70 & 0.70 & 0.01 & 0.98 \\
\hline Plamitic (C16:0) & 19.41 & 18.99 & 19.45 & 21.02 & 0.41 & 0.35 \\
\hline Stearic (C18:0) & 7.26 & 7.54 & 7.55 & 7.53 & 0.14 & 0.91 \\
\hline Archidic (C20:0) & 0.92 & 0.88 & 0.89 & 0.95 & 0.02 & 0.76 \\
\hline Palmitoleic (C16:1) & 3.18 & 3.19 & 3.40 & 3.21 & 0.06 & 0.64 \\
\hline Oleic (C18:1) & 20.59 & 20.31 & 20.63 & 18.82 & 0.47 & 0.52 \\
\hline Linoleic (C18:2n-6) & 18.29 & 17.11 & 16.85 & 18.41 & 0.36 & 0.33 \\
\hline$\alpha$-Linolenic (C18:3 n-3) & 1.71 & 1.73 & 1.57 & 1.71 & 0.03 & 0.32 \\
\hline Stearidonic acid (C18:4n3) & 0.92 & 0.89 & 0.85 & 0.97 & 0.01 & 0.162 \\
\hline $\operatorname{EPA}(\mathrm{C} 20: 5 n-3)$ & $0.91^{b}$ & $0.97^{b}$ & $2.19^{\mathrm{a}}$ & $1.69^{\mathrm{a}}$ & 0.15 & 0.001 \\
\hline DHA (C22:6 n-3) & $1.11^{\mathrm{b}}$ & $1.19^{b}$ & $2.40^{\mathrm{a}}$ & $2.20^{\mathrm{a}}$ & 0.15 & $<0.001$ \\
\hline Arachidonic acid(C20:4n6) & $1.04^{b}$ & $1.21^{\mathrm{b}}$ & $2.56^{\mathrm{a}}$ & $2.25^{\mathrm{a}}$ & 0.17 & $<0.001$ \\
\hline Total SFA & 28.29 & 28.03 & 28.61 & 30.31 & 0.45 & 0.31 \\
\hline MUFA & 23.78 & 23.51 & 24.04 & 22.03 & 0.47 & 0.49 \\
\hline PUFA & $23.93^{b}$ & $23.13^{b}$ & $26.45^{\mathrm{a}}$ & $27.7^{\mathrm{a}}$ & 0.58 & 0.003 \\
\hline PUFA/SFA & 0.84 & 0.82 & 0.92 & 0.91 & 0.02 & 0.24 \\
\hline Total n-3 FA & $4.59^{b}$ & $4.80^{b}$ & $7.02^{\mathrm{a}}$ & $6.84^{\mathrm{a}}$ & 0.29 & $<0.001$ \\
\hline
\end{tabular}

${ }^{\mathrm{a}-\mathrm{b}}$ Means within a row not sharing a common superscript differ significantly when $(p<0.05)$. SEM: standard error of mean; EPA: Eicosapentaenoic; DHA: Docosahexaenoic; SFA: saturated fatty acids; MUFA: monounsaturated fatty acids; PUFA: polyunsaturated fatty acids; n-3 FA: omega-3 fatty acids; Group 1: control; Group 2: Chlorella vulgaris (CV)-supplemented group; Group 3: Spirulina platensis (SP)-supplemented group; Group 4: Amphora coffeaformis (AC)-supplemented group.

The influence of dietary microalgae on the amino acid profile in the breast muscles is displayed in Table 6. The levels of essential amino acids (lysine, methionine, tryptophan, and histidine) and aspartic acid were significantly increased $(p<0.001)$ in breast muscle of broilers supplemented with 
either SP or AC compared to that in birds received CV which remained comparable to control (Table 6). Other amino acid concentrations remained unchanged significantly $(p>0.05)$ in all experimental groups compared to the control (Table 6).

Table 6. Profiles of amino acids in breast muscle of broilers chickens fed different species of microalgae for 32 days.

\begin{tabular}{|c|c|c|c|c|c|c|}
\hline \multirow{2}{*}{ Amino Acids } & \multicolumn{4}{|c|}{ Dietary Treatment } & \multirow{2}{*}{ SEM } & \multirow{2}{*}{$p$ Values } \\
\hline & Group 1 & Group 2 & Group 3 & Group 4 & & \\
\hline Lysine & $6.04^{b}$ & $6.39^{b}$ & $7.18^{a}$ & $7.02^{a}$ & 0.15 & 0.009 \\
\hline Leucine & 6.80 & 6.73 & 7.63 & 7.55 & 0.16 & 0.09 \\
\hline Isoleucine & 3.72 & 3.86 & 4.40 & 3.59 & 0.11 & 0.06 \\
\hline Valine & 4.82 & 4.51 & 4.91 & 4.32 & 0.11 & 0.27 \\
\hline Methionine & $1.97^{b}$ & $1.87^{\mathrm{b}}$ & $2.33^{\mathrm{a}}$ & $2.23^{\mathrm{a}}$ & 0.06 & 0.04 \\
\hline Phenyl alanine & 2.10 & 2.15 & 2.51 & 2.29 & 0.07 & 0.16 \\
\hline Tryptophan & $2.53^{b}$ & $2.50^{b}$ & $2.92^{\mathrm{a}}$ & $2.86^{\mathrm{a}}$ & 0.07 & 0.002 \\
\hline Threonine & 3.04 & 3.03 & 3.51 & 3.13 & 0.09 & 0.24 \\
\hline Histidine & $3.04^{b}$ & $3.18^{b}$ & $3.82^{\mathrm{a}}$ & $3.75^{\mathrm{a}}$ & 0.10 & 0.02 \\
\hline Arginine & 5.47 & 4.98 & 5.66 & 5.29 & 0.12 & 0.26 \\
\hline Glycine & 4.48 & 4.05 & 4.28 & 4.22 & 0.10 & 0.56 \\
\hline Proline & 1.68 & 1.72 & 1.51 & 1.61 & 0.03 & 0.12 \\
\hline Serine & 2.71 & 2.86 & 2.58 & 2.78 & 0.07 & 0.60 \\
\hline Aspartic acid & $8.28^{b}$ & $8.38^{\mathrm{b}}$ & $9.38^{\mathrm{a}}$ & $9.73^{\mathrm{a}}$ & 0.18 & 0.01 \\
\hline Glutamic acid & 15.96 & 16.77 & 16.58 & 16.26 & 0.69 & 0.12 \\
\hline Alanine & 5.26 & 5.32 & 5.35 & 5.06 & 0.12 & 0.88 \\
\hline
\end{tabular}

$\mathrm{a}-\mathrm{b}$ Means within a row not sharing a common superscript differ significantly when $(p<0.05)$. SEM: standard error of mean; Group 1: control; Group 2: Chlorella vulgaris (CV)-supplemented group; Group 3: Spirulina platensis (SP)-supplemented group; Group 4: Amphora coffeaformis (AC)-supplemented group.

\subsection{Effect of Dietary Microalgae on Antioxidant Status of Breast Muscles}

The effect of dietary microalgae on the levels of MDA, SOD, and PC is presented in Table 7. All studied microalgae species induced a significant reduction of malondialdehyde (MDA) and protein carbonyle (PC) levels with significant increase in superoxide dismutase (SOD) activities in the breast muscle of broiler chickens compared to the control significantly.

Table 7. Antioxidant status in breast muscle of broilers chickens fed different species of microalgae for 32 days.

\begin{tabular}{|c|c|c|c|c|c|c|}
\hline \multirow{2}{*}{ Muscle Tissue } & \multicolumn{4}{|c|}{ Dietary Treatment } & \multirow{2}{*}{ SEM } & \multirow{2}{*}{$p$ Values } \\
\hline & Group 1 & Group 2 & Group 3 & Group 4 & & \\
\hline MDA (nmol/g tissue) & $19.76^{\mathrm{a}}$ & $14.32^{b}$ & $13.31^{\mathrm{b}}$ & $13.61^{\mathrm{b}}$ & 0.62 & 0.007 \\
\hline SOD (U/g tissue) & $36.94^{b}$ & $55.08^{a}$ & $60.70^{a}$ & $53.39^{\mathrm{a}}$ & 3.88 & 0.02 \\
\hline PC (nmol/mg protein) & $33.66^{\mathrm{a}}$ & $26.55^{b}$ & $25.41^{b}$ & $26.10^{b}$ & 1.18 & 0.01 \\
\hline
\end{tabular}

\subsection{Effect of Dietary Microalgae on Meat Quality Parameters of Breast Muscles}

Data that explore the effect of dietary microalgae on meat quality parameters of breast muscles of broiler chickens are shown in Table 8 . All studied microalgae reduced the cooking loss, and had low aerobic plate count after first day (APC 1st day) and after 5 days APC ( 5 th days) $(p<0.05)$ compared to the control (Table 8). Further, the differences between initial and 5th day APCs in breast muscle of broilers fed SP and AC was significantly lower $(p<0.05)$ than CV supplemented group which remained 
comparable to the control (Table 8). Other meat quality parameters (i.e., $\mathrm{pH}, \mathrm{WHC}$, and thawing loss) remained unchanged significantly $(p>0.05)$ in all experimental groups compared to the control (Table 8).

Table 8. Meat quality parameters in breast muscle of broilers chickens fed different species of microalgae for 32 days.

\begin{tabular}{|c|c|c|c|c|c|c|}
\hline \multirow{2}{*}{ Parameters } & \multicolumn{4}{|c|}{ Dietary Treatment } & \multirow{2}{*}{ SEM } & \multirow{2}{*}{$p$ Values } \\
\hline & Group 1 & Group 2 & Group 3 & Group 4 & & \\
\hline $\mathrm{pH} 24$ & 5.74 & 5.86 & 5.93 & 5.81 & 0.03 & 0.29 \\
\hline Water holding capacity (\%) & 73.70 & 73.49 & 78.86 & 69.79 & 2.09 & 0.59 \\
\hline Thawing loss $(\%)$ & 5.06 & 5.20 & 4.77 & 4.06 & 0.70 & 0.96 \\
\hline Cooking loss $(\%)$ & $18.63^{\mathrm{a}}$ & $12.56^{\mathrm{b}}$ & $12.39^{b}$ & $11.69^{b}$ & 1.01 & 0.02 \\
\hline APC 1st day (log cfu/gm) & $5.37^{\mathrm{a}}$ & $4.30^{\mathrm{b}}$ & $4.62^{b}$ & $4.93^{\mathrm{b}}$ & 0.13 & 0.002 \\
\hline APC 5th day (log cfu/gm) & $6.54^{\mathrm{a}}$ & $5.50^{b}$ & $5.59^{b}$ & $5.79^{b}$ & 0.14 & $<0.001$ \\
\hline APC's growing volumes $(\log \mathrm{cfu} / \mathrm{gm})$ & $1.17^{\mathrm{a}}$ & $1.20^{\mathrm{a}}$ & $0.97^{b}$ & $0.85^{b}$ & 0.12 & 0.098 \\
\hline
\end{tabular}

\section{Discussion}

\subsection{Effect of Dietary Microalgae on Growth Performance Parameters}

The incorporation of microalgae in animal diet offers a chance to enhance growth performance and meat quality but the results extensively based on chemical constituent, level of inclusion, types of microalgae, and environmental conditions during growth [41,42]. In the current study, the effects of three species of microalgae (CV, SP, and AC) have been compared at five axis (growth promotion parameters, meat composition of fatty and amino acids, meat antioxidant status, and meat quality parameters) in broiler chickens. The Cobb 500 performance guide would result in an average body weight of $2369 \mathrm{~g}$. However, in the current study, the control line reached an average body weight of $1844 \mathrm{~g}$. This may be attributed to feeding these birds with basal diet of mash ground feed without any additives. The supplemented basal diet was prepared in the college laboratory and not prepared in the feed mill, so the feeds were not pelleted or crumbled. In addition, the basal diet was not treated with steam during processing. These deviations from Cobb 500 dietary recommendations may be the reasons that stand behind the observed lower body weight of the control birds in the current study compared to that described in the Cobb 500 performance guide. In the current study, AC shared CV in the superiority of increasing final body weight and body weight gain compared to SP which remained comparable to the control. This current finding supported by the previous published reports $[14,43]$ in broilers chickens. Furthermore, addition of fermented CV in diets of duck was associated with positive increases in body weight gain [44]. In the current study, FCR remained comparable to the control whatever the microalgae added. On the contrary, lower FCR was observed in birds fed CV and AC compared to control in broilers [45] and layers [46]. These diverse results reflect the role of microalgae types and the level of inclusion. As explained above, it can be said that AC and CV were preferable to SP in growth promotion of broilers when all were compared to the control.

\subsection{Effect of Dietary Microalgae on Profiles of Fatty and Amino Acids in Breast Muscles}

The observed insignificant changes in SFA and MUFA concentration in breast muscles of birds fed studied microalgae diets compared to control were in agreement with previous published reports in animals $[42,47,48]$. On the other hand, the detected significant increase in the levels of EPA, DHA, n-3 FA, PUFA, and arachidonic acid in breast muscle of broilers chickens fed SP and AC compared to those of birds fed CV and control birds was consistent with and supported by the previous published 
data in animals [49] and broiler chickens [50,51]. The analysis of fatty acids of studied microalgae indicated that the fatty acid profile in the microalgae differed than that estimated in meat (Table 1). In this context, CV was rich in $\omega-3$ fatty acids than that of SP and AC. However, these fatty acids were higher in the meat of birds fed SP and AC supplemented diets than that of birds fed CV supplemented diet. Furthermore, the analysis of amino acids of studied microalgae indicated higher methionine and lysine concentrations in SP and AC than that of CV (Table 2). Additionally, high contents of methionine and lysine in SP and AC microalgae reflected positively on their levels in meat of birds fed SP and AC supplemented diets than that of birds fed CV supplemented diet. Methionine increases the concentration of total $\omega-3$ fatty acids in the breast muscle of broiler chicks [52]. In addition, lysine enhances the accumulation of $0-3$ fatty acids in meat of broiler chickens [52]. Therefore, the high level of n-3 fatty acids in meat of birds fed a diet supplemented with either SP or AC may be attributed to their high methionine and lysine contents compared to that of $\mathrm{CV}$. In addition, further future studies are essential to confirm the mechanism by which SP and AC increase the $\omega-3$ fatty acids in broiler meat. Focused the on above discussed results, it can be said that AC and SP were preferable to CV in increasing essential fatty acid contents in broilers meat. The estimated significant increase in the levels of essential amino acids (lysine, methionine, tryptophan, and histidine) in breast muscles of broilers chickens fed SP and AC than CV and control may be attributed to their higher contents of total proteins and essential amino acids [53]. In addition, the existence of powerful antioxidants agents in SP and AC may play a role in inhibition of amino acids oxidation, which may produce during protein degradation [54]. Based on the discussion of meat amino acid profile axis, it can be said that AC and SP favorably increased the essential amino acid contents in broilers meat over CV and control.

\subsection{Effect of Dietary Microalgae on Antioxidant Status of Breast Muscles}

MDA was documented as indicator of lipid peroxidation [55]. The present findings revealed a significant decrease in MDA values in muscle tissue of birds supplemented with all species of microalgae (CV, SP, and AC) compared to the control. This finding is in agreement with previous works describing the high antioxidant capacity of SP in broiler chickens [56] which was attributed to its contents of beta-carotene zeaxanthin, phycocyanin, and allophycocyanin [57]. In addition, the higher concentration of $\beta$-carotene, fucoxanthin, and phenolic compounds of antioxidant activity in AC has been described earlier [58]. Furthermore, $\mathrm{CV}$ extract played a role in lowering lipid peroxidation in rats exposed to naphthalene toxicity [59]. Superoxide dismutase (SOD) is the most essential antioxidant enzyme, which plays a vital role in the removal of superoxide anion [60] in animals. The present finding of the significant increase in SOD values in muscle tissue of birds supplemented with all species of microalgae $(\mathrm{CV}, \mathrm{SP}$, and $\mathrm{AC})$ compared to the control may indicate that there was a great correlation between addition of microalgae and improvement of antioxidant capacity as previously reported [56]. It was reported that the reactive oxygen species, which may produce during lipid peroxidation, has the ability to oxidize the protein side chains [61]. Thereby, any condition influencing lipid peroxidation may also lead to protein oxidation [62]. In chickens, the degree of protein oxidation was estimated by carbonyl content which is related to lipid oxidation [62]. As observed in the current study, protein carbonyl (PC) levels were decreased significantly in breast meat of chickens supplemented with all species of microalgae compared to control. This effect may be attributed to the higher antioxidant contents of microalgae [56] which may prevent oxidation of protein and free amino acids into PC. Based on the discussion of meat antioxidant status axis, it can be said that all microalgae species improved the antioxidant status in the breast muscle of broiler chickens with an equal efficiency compared to the control.

\subsection{Effect of Dietary Microalgae on Meat Quality Parameters of Breast Muscles}

The detected reduced level of APC 1st day and APC 5th days in breast muscle of broiler chickens fed microalgae compared to the control indicated their antimicrobial activities that attributed to high contents of bioactive antimicrobial and antioxidant peptides $[58,63,64]$. Additionally, the preservative 
activity of SP and AC was stronger than that of $\mathrm{CV}$ which remained comparable to the control as reflected on estimated APC's growing volumes. High levels of bioactive and antioxidant peptides $[58,63,64]$ or eicosapentaenoic acids (EPA) may be correlated with antimicrobial capacity, particularly EPA because it is significantly higher in SP and AC than in control and CV groups. SP had higher antioxidant activity than CV, which may also contribute to a higher preservative effect of SP than CV [65]. Nevertheless, the exact compound and mechanism of action remain unknown [66]. Based on the discussion of meat quality axis, it can be said that all supplemented microalgae species, notably SP and AC, improved the technological (losses in thawing and cooking) and keeping qualities of broiler chickens meat compared to the control. In general and based on the whole discussion section, the three studied species of microalgae improved the antioxidant status of breast muscle in broiler chickens. However, AC shared $\mathrm{CV}$ in the superiority for growth promotion in broiler chickens. Furthermore, AC shared SP in the superiority for increment of the essential fatty and amino acids concentrations in the breast meat of broiler chickens. AC shared SP in the superiority of reduction of microbial growth in the breast muscle of broilers chickens compared to $\mathrm{CV}$ which remained comparable to the control as reflected on estimated APC's growing volumes.

\section{Conclusions}

The current results may recommend supplementation of the studied microalgae species to broilers chickens' diet for improvement of performance parameters, profiles of fatty and amino acids, antioxidant status, and meat quality. The current study may arrange the superiority of studied microalgae into Amphora coffeaformis (AC) $>$ Spirulina platensis (SP) $>$ Chlorella vulgaris $(\mathrm{CV})$ as feed additives in broiler chickens. However, future studies are required to evaluate the effect of combined supplementation of the studied microalgae on growth and meat quality of broiler chickens.

Author Contributions: S.E.-B., A.S., W.K. and S.S. carried out the experimental design, participated in the performance experiment, biochemical analysis of fatty and amino acids, and antioxidant. I.S. carried out the analysis of meat quality and analysis of fatty and amino acids. A.S., W.K., S.S., I.S. carried out the diet preparation, management procedures and statistical analysis. O.A.-F., O.E.-G., I.A. and K.A. shared in managemental, biochemical analysis of antioxidants. All authors drafted and approved the final version of the manuscript.

Funding: This research was funded by the Deanship of Scientific Research, King Faisal University, Saudi Arabia Nasher track (Grant \# 186370). The current study is a collaborative project between King Faisal University, Saudi Arabia, and Benha University, Egypt. This project was funded by Deanship of Scientific Research, King Faisal University, Saudi Arabia, Nasher track (Grant \# 186370). Deanship of Scientific Research, King Faisal University, Saudi Arabia approved the design of the study, provided the total fund of the study.

Acknowledgments: The authors would like to express a deep appreciation and thanks to the Deanship of Scientific Research, King Faisal University, Saudi Arabia Nasher track for its financial support of this work (Grant \# 186370).

Conflicts of Interest: The authors declare no conflict of interest.

\section{References}

1. Kralik, G.; Kralik, Z.; Grčević, M.; Hanžek, D. Quality of Chicken Meat. In Animal Husbandry and Nutrition; Yucel, B., Ed.; Intechopen: London, England, 2018; p. 63. [CrossRef]

2. Gaskins, H.R.; Collier, C.T.; Anderson, D.B. Antibiotics as growth promotants: Mode of action. Anim. Biotechnol. 2002, 13, 29-42. [CrossRef] [PubMed]

3. Abdel Aziz, E.A.; El-Nabtity, S.M.; El Barawy, A.A.M.; Saleh, M.A.M. Residues of Ceftiofur Sodium in Rabbit Tissues. Zagazig Vet. J. 2017, 45, 104-111. [CrossRef]

4. Founou, L.L.; Founou, R.C.; Essack, S.Y. Antibiotic Resistance in the Food Chain: A Developing CountryPerspective. Front. Microbiol. 2016, 7, 1881. [CrossRef]

5. Thanner, S.; Drissner, D.; Walsh, F. Antimicrobial Resistance in Agriculture. mBio 2016, 7, e02227-15. [CrossRef] [PubMed]

6. Venter, H.; Henningsen, M.L.; Begg, S.L. Antimicrobial resistance in healthcare, agriculture and the environment: The biochemistry behind the headlines. Essays Biochem. 2017, 61, 1-10. [CrossRef] [PubMed] 
7. Lagha, A.B.; Haas, B.; Gottschalk, M.; Grenier, D. Antimicrobial potential of bacteriocins in poultry and swine production. Vet. Res. 2017, 48, 22. [CrossRef] [PubMed]

8. Smith, D.L.; Harris, A.D.; Johnson, J.A.; Silbergeld, E.K.; Morris, J.G., Jr. Animal antibiotic use has an early but important impact on the emergence of antibiotic resistance in human commensal bacteria. Proc. Natl. Acad. Sci. USA 2002, 99, 6434-6439. [CrossRef]

9. Kang, H.K.; Lee, H.H.; Seo, C.H.; Park, Y. Antimicrobial and Immunomodulatory Properties and Applications of Marine-Derived Proteins and Peptides. Mar. Drugs 2019, 17, 350. [CrossRef]

10. Lauritano, C.; Andersen, J.H.; Hansen, E.; Albrigtsen, M.; Escalera, L.; Esposito, F.; Helland, K.; Hanssen, K.Ø.; Romano, G.; Ianora, A. Bioactivity screening of microalgae for antioxidant, anti-inflammatory, anticancer, anti-diabetes, and antibacterial activities. Front. Mar. Sci. 2016, 3, 68. [CrossRef]

11. Abouelezz, F. Evaluation of spirulina algae (spirulina platensis) as a feed supplement for Japanese quail: Nutritional effects on growth performance, egg production, egg quality, blood metabolites, sperm-egg penetration and fertility. Poult. Sci. 2017, 37, P707-P719. [CrossRef]

12. Świątkiewicz, S.; Arczewska-Włosek, A.; Józefiak, D. Application of microalgae biomass in poultry nutrition. World Poult. Sci. J. 2015, 71, 663-672. [CrossRef]

13. Khan, Z.; Bhadouria, P.; Bisen, P. Nutritional and therapeutic potential of Spirulina. Curr. Pharm. Biotechnol. 2005, 6, 373-379. [CrossRef]

14. Kang, H.; Salim, H.; Akter, N.; Kim, D.; Kim, J.; Bang, H.; Kim, M.; Na, J.; Hwangbo, J.; Choi, H. Effect of various forms of dietary Chlorella supplementation on growth performance, immune characteristics, and intestinal microflora population of broiler chickens. J. Appl. Poult. Res. 2013, 22, 100-108. [CrossRef]

15. Deng, R.; Chow, T.J. Hypolipidemic, antioxidant, and antiinflammatory activities of microalgae Spirulina. Cardiovasc. Ther. 2010, 28, e33-e45. [CrossRef]

16. Holman, B.; Malau-Aduli, A. Spirulina as a livestock supplement and animal feed. J. Anim. Physiol. Anim. Nutr. 2013, 97, 615-623. [CrossRef]

17. Zahroojian, N.; Moravej, H.; Shivazad, M. Effects of dietary marine algae (Spirulina platensis) on egg quality and production performance of laying hens. J. Agric. Sci. Technol. 2013, 15, 1353-1360.

18. Sugiharto, S.; Yudiarti, T.; Isroli, I.; Widiastuti, E. Effect of feeding duration of Spirulina platensis on growth performance, haematological parameters, intestinal microbial population and carcass traits of broiler chicks. S. Afr. J. Anim. Sci. 2018, 48, 98-107. [CrossRef]

19. Lee, S.-H.; Karawita, R.; Affan, A.; Lee, J.-B.; Lee, K.-W.; Lee, B.-J.; Kim, D.-W.; Jeon, Y.-J. Potential of Benthic Diatoms Achnanthes longipes, Amphora coffeaeformisand Navicula sp.(Bacillariophyceae) as Antioxidant Sources. Algae 2009, 24, 47-55. [CrossRef]

20. Renaud, S.M.; Thinh, L.-V.; Parry, D.L. The gross chemical composition and fatty acid composition of 18 species of tropical Australian microalgae for possible use in mariculture. Aquaculture 1999, 170, 147-159. [CrossRef]

21. Schiavone, A.; Chiarini, R.; Marzoni, M.; Castillo, A.; Tassone, S.; Romboli, I. Breast meat traits of Muscovy ducks fed on a microalga (Crypthecodinium cohnii) meal supplemented diet. Br. Poult. Sci. 2007, 48, 573-579. [CrossRef]

22. Pina-Pérez, M.C.; Rivas, A.; Martínez, A.; Rodrigo, D. Antimicrobial potential of macro and microalgae against pathogenic and spoilage microorganisms in food. Food Chem. 2017, 235, 34-44. [CrossRef]

23. Al-Saif, S.S.A.-1.; Abdel-Raouf, N.; El-Wazanani, H.A.; Aref, I.A. Antibacterial substances from marine algae isolated from Jeddah coast of Red sea, Saudi Arabia. Saudi J. Biol. Sci. 2014, 21, 57-64. [CrossRef] [PubMed]

24. Amaro, H.M.; Guedes, A.C.; Malcata, F.X. Antimicrobial activities of microalgae: An invited review. In Science against Microbial Pathogens: Communicating Current Research and Technological Advances; Formatex Research Center: Badajoz, Spain, 2011; Volume 3, pp. 1272-1284.

25. NRC (National Research Council). Nutrient Requirements of Poultry: 1994; National Academies Press: Washington, DC, USA, 1994.

26. Folch, J.; Lees, M.; Sloane Stanley, G.H. A simple method for the isolation and purification of total lipides from animal tissues. J. Biol. Chem. 1957, 226, 497-509.

27. Radwan, O.K.; Ahmed, R.F. Amendment effect of resveratrol on diclofenac idiosyncratic toxicity: Augmentation of the anti-inflammatory effect by assessment of Arachidonic acid and IL-1 $\beta$ levels. J. Appl. Pharm. Sci. 2016, 6, 170-177. [CrossRef] 
28. Salah, A.S.; Ahmed-Farid, O.A.; El-Tarabany, M.S. Carcass yields, muscle amino acid and fatty acid profiles, and antioxidant indices of broilers supplemented with synbiotic and/or organic acids. J. Anim. Physiol. Anim. Nutr. 2019, 103, 41-52. [CrossRef]

29. Hughes, M.C.; Kerry, J.P.; Arendt, E.K.; Kenneally, P.M.; McSweeney, P.L.; O’Neill, E.E. Characterization of proteolysis during the ripening of semi-dry fermented sausages. Meat Sci. 2002, 62, 205-216. [CrossRef]

30. Yi, Z.; Li, X.; Luo, W.; Xu, Z.; Ji, C.; Zhang, Y.; Nie, Q.; Zhang, D.; Zhang, X. Feed conversion ratio, residual feed intake and cholecystokinin type A receptor gene polymorphisms are associated with feed intake and average daily gain in a Chinese local chicken population. J. Anim. Sci. Biotechnol. 2018, 9, 50. [CrossRef]

31. Overmyer, K.A.; Thonusin, C.; Qi, N.R.; Burant, C.F.; Evans, C.R. Impact of anesthesia and euthanasia on metabolomics of mammalian tissues: Studies in a C57BL/6J mouse model. PLoS ONE 2015, 10, e0117232. [CrossRef] [PubMed]

32. Ali, E.H.; Elgoly, A.H. Combined prenatal and postnatal butyl paraben exposure produces autism-like symptoms in offspring: Comparison with valproic acid autistic model. Pharmacol. Biochem. Behav. 2013, 111, 102-110. [CrossRef]

33. Abd-Elrazek, A.M.; Ahmed-Farid, O.A.H. Protective effect of L-carnitine and L-arginine against busulfan-induced oligospermia in adult rat. Andrologia 2018, 50. [CrossRef]

34. Ahmed-Farid, O.A.H.; Nasr, M.; Ahmed, R.F.; Bakeer, R.M. Beneficial effects of curcumin nano-emulsion on spermatogenesis and reproductive performance in male rats under protein deficient diet model: Enhancement of sperm motility, conservancy of testicular tissue integrity, cell energy and seminal plasma amino acids content. J. Biomed. Sci. 2017, 24, 66. [CrossRef] [PubMed]

35. Castegna, A.; Drake, J.; Pocernich, C.; Butterfield, D.A. Protein carbonyl levels-An assessment of protein oxidation. In Methods in Biological Oxidative Stress; Springer: Berlin/Heidelberg, Germany, 2003; pp. 161-168.

36. Honikel, K.; Hamm, R. Measurement of water-holding capacity and juiciness. In Quality Attributes and Their Measurement in Meat, Poultry and Fish Products; Springer: Berlin/Heidelberg, Germany, 1994; pp. 125-161.

37. Honikel, K.O. Reference methods for the assessment of physical characteristics of meat. Meat Sci. 1998, 49, 447-457. [CrossRef]

38. Sabike, I.I.; Fujikawa, H.; Edris, A.M. The Growth Kinetics of Salmonella Enteritidis in Raw Ground Beef. Biocontrol Sci. 2015, 20, 185-192. [CrossRef] [PubMed]

39. Sutton, S. Accuracy of plate counts. J. Valid. Technol. 2011, 17, 42-46.

40. Duncan, D.B. Multiple range and multiple F tests. Biometrics 1955, 11, 1-42. [CrossRef]

41. Habib, M.A.B. Review on Culture, Production and Use of Spirulina as Food for Humans and Feeds for Domestic Animals and Fish; Food and Agriculture Organization of the United Nations: Rome, Italy, 2008.

42. Madeira, M.S.; Cardoso, C.; Lopes, P.A.; Coelho, D.; Afonso, C.; Bandarra, N.M.; Prates, J.A. Microalgae as feed ingredients for livestock production and meat quality: A review. Livest. Sci. 2017, 205, 111-121. [CrossRef]

43. Dlouhá, G.; Sevcikova, S.; Dokoupilova, A.; Zita, L.; Heindl, J.; Skrivan, M. Effect of dietary selenium sources on growth performance, breast muscle selenium, glutathione peroxidase activity and oxidative stability in broilers. Czech J. Anim. Sci. 2008, 53, 265. [CrossRef]

44. Oh, S.T.; Zheng, L.; Kwon, H.J.; Choo, Y.K.; Lee, K.W.; Kang, C.W.; An, B.K. Effects of Dietary Fermented Chlorella vulgaris (CBT((R))) on Growth Performance, Relative Organ Weights, Cecal Microflora, Tibia Bone Characteristics, and Meat Qualities in Pekin Ducks. Asian Australas. J. Anim. Sci. 2015, 28, 95-101. [CrossRef]

45. Rezvani, M.; Zaghari, M.; Moravej, H. A survey on Chlorella vulgaris effect's on performance and cellular immunity in broilers. Int. J. Agric. Sci. Res. 2012, 3, 9-15.

46. Englmaierová, M.; Skrivan, M.; Bubancová, I. A comparison of lutein, spray-dried Chlorella, and synthetic carotenoids effects on yolk colour, oxidative stability, and reproductive performance of laying hens. Czech J. Anim. Sci. 2013, 58, 412-419. [CrossRef]

47. Sardi, L.; Martelli, G.; Lambertini, L.; Parisini, P.; Mordenti, A. Effects of a dietary supplement of DHA-rich marine algae on Italian heavy pig production parameters. Livest. Sci. 2006, 103, 95-103. [CrossRef]

48. Vossen, E.; Raes, K.; Van Mullem, D.; De Smet, S. Production of docosahexaenoic acid (DHA) enriched loin and dry cured ham from pigs fed algae: Nutritional and sensory quality. Eur. J. Lipid Sci. Technol. 2017, 119, 1600144. [CrossRef] 
49. Kalbe, C.; Priepke, A.; Nurnberg, G.; Dannenberger, D. Effects of long-term microalgae supplementation on muscle microstructure, meat quality and fatty acid composition in growing pigs. J. Anim. Physiol. Anim. Nutr. 2019, 103, 574-582. [CrossRef]

50. Moran, C.A.; Currie, D.; Keegan, J.D.; Knox, A. Tolerance of Broilers to Dietary Supplementation with High Levels of the DHA-Rich Microalga, Aurantiochytrium Limacinum: Effects on Health and Productivity. Animals 2018, 8, 180. [CrossRef]

51. Yan, L.; Kim, I.H. Effects of dietary $\omega-3$ fatty acid-enriched microalgae supplementation on growth performance, blood profiles, meat quality, and fatty acid composition of meat in broilers. J. Appl. Anim. Res. 2013, 41, 392-397. [CrossRef]

52. Moghadam, M.B.; Shehab, A.; Cherian, G. Methionine supplementation augments tissue n-3 fatty acid and tocopherol content in broiler birds fed flaxseed. Anim. Feed Sci. Technol. 2017, 228, 149-158. [CrossRef]

53. Kiani, A.; Sharifi, S.D.; Ghazanfari, S. Influence of Canola Oil and Lysine Supplementation Diets on Growth Performance and Fatty Acid Composition of Meat in Broiler Chicks. Int. J. Biol. Biomol. Agric. Food Biotechnol. Eng. 2017, 11, 134-140.

54. Evans, A.M.; Smith, D.L.; Moritz, J.S. Effects of algae incorporation into broiler starter diet formulations on nutrient digestibility and 3 to $21 \mathrm{~d}$ bird performance. J. Appl. Poult. Res. 2015, 24, 206-214. [CrossRef]

55. Perenlei, G.; Tojo, H.; Okada, T.; Kubota, M.; Kadowaki, M.; Fujimura, S. Effect of dietary astaxanthin rich yeast, Phaffia rhodozyma, on meat quality of broiler chickens. Anim. Sci. J. 2014, 85, 895-903. [CrossRef]

56. Droge, W. Free radicals in the physiological control of cell function. Physiol. Rev. 2002, 82, 47-95. [CrossRef]

57. Mirzaie, S.; Zirak-Khattab, F. Effects of dietary Spirulina on antioxidant status, lipid profile, immune response and performance characteristics of broiler chickens reared under high ambient temperature. Asian-Australas. J. Anim. Sci. 2018, 31, 556-563. [CrossRef]

58. Pinero Estrada, J.E.; Bermejo Bescos, P.; Villar del Fresno, A.M. Antioxidant activity of different fractions of Spirulina platensis protean extract. Farmaco 2001, 56, 497-500. [CrossRef]

59. Goiris, K.; Muylaert, K.; Fraeye, I.; Foubert, I.; De Brabanter, J.; De Cooman, L. Antioxidant potential of microalgae in relation to their phenolic and carotenoid content. J. Appl. Phycol. 2012, 24, 1477-1486. [CrossRef]

60. Vijayavel, K.; Anbuselvam, C.; Balasubramanian, M.P. Antioxidant effect of the marine algae Chlorella vulgaris against naphthalene-induced oxidative stress in the albino rats. Mol. Cell. Biochem. 2007, 303, 39-44. [CrossRef]

61. Li, Y.; Liu, S. Reducing lipid peroxidation for improving colour stability of beef and lamb: On-farm considerations. J. Sci. Food Agric. 2012, 92, 719-726. [CrossRef]

62. Refsgaard, H.H.; Tsai, L.; Stadtman, E.R. Modifications of proteins by polyunsaturated fatty acid peroxidation products. Proc. Natl. Acad. Sci. USA 2000, 97, 611-616. [CrossRef]

63. Xiao, S.; Zhang, W.G.; Lee, E.J.; Ma, C.W.; Ahn, D.U. Effects of diet, packaging, and irradiation on protein oxidation, lipid oxidation, and color of raw broiler thigh meat during refrigerated storage. Poult. Sci. 2011, 90, 1348-1357. [CrossRef]

64. Bleakley, S.; Hayes, M. Algal Proteins: Extraction, Application, and Challenges Concerning Production. Foods 2017, 6, 33. [CrossRef]

65. Beaulieu, L. Insights into the Regulation of Algal Proteins and Bioactive Peptides Using Proteomic and Transcriptomic Approaches. Molecules 2019, 24, 1708. [CrossRef]

66. Wu, L.C.; Ho, J.A.; Shieh, M.C.; Lu, I.W. Antioxidant and antiproliferative activities of Spirulina and Chlorella water extracts. J. Agric. Food Chem. 2005, 53, 4207-4212. [CrossRef]

(C) 2020 by the authors. Licensee MDPI, Basel, Switzerland. This article is an open access article distributed under the terms and conditions of the Creative Commons Attribution (CC BY) license (http://creativecommons.org/licenses/by/4.0/). 